\title{
Personal Public Transport in Australia: Developments and Prospects
}

\author{
Garry Glazebrook \\ Booz-Allen \& Hamilton (Aust) Limited \\ Sydney, Australia \\ Sam Subramaniam \\ Booz-Allen \& Hamilton Limited, \\ McLean, Virginia
}

\begin{abstract}
$\overline{\text { Abstract }}$
The environmental, social, and economic cost of current car dependence is well known. But people tend to be unwilling to forgo the convenience of private transport. Personal Public Transport (PPT) is a new concept combining the environmental advantages of public transport with the flexibility of the car. The key elements of PPT are new multi-hire modes provided by maxitaxis and taxibuses to supplement single-hire taxis and scheduled services; integration of all modes into a single system; and provision of real-time information and booking systems enabling individual passengers to communicate with the transport system, whether they be at home, on street or in transit.

This paper describes how PPT will integrate various technologies, such as automatic vehicle location systems, multi-hire dispatching systems, advanced passenger information systems, and smart card billing systems, together with some of the latest developments in Personal Public Transport.
\end{abstract}


While the technical aspects of PPT are expected to be solvable relatively easily, establishing a complete PPT system will require institutional and regulatory change and a willingness to innovate by both transport operators and regulators. The paper describes changes occurring in Australia in the taxi and bus industries and in regulatory arrangements that will facilitate PPT, and sets out models for establishing PPT systems. It also assesses the potential for PPT from a marketing perspective and its relationship to new developments in urban planning. The paper concludes with a prognosis of how urban transport systems will evolve under the influence of environmental pressures, social values and technological developments, and of how our cities will emerge from the mass transit and private transport eras of the past to the new era of Personal Public Transport and Personal Rapid Transit.

\section{Introduction}

\section{Public Versus Private Transport}

Private cars provide their owners with many private mobility benefits, including:

- the convenience of traveling whenever they want,

- the flexibility of traveling wherever they want, and the ability to change their destination easily, and

- comfort, privacy and the ability to travel alone or with people of their choosing.

In addition, the car has often been associated with status, independence, and a feeling of freedom. These mobility and other benefits have jointly underpinned the remarkable popularity of the car, and its current dominance of urban transport systems in many cities in the world.

However, recent surveys suggest that the love affair with the car may be ending in countries such as Australia, the United States, and Europe, where cars are now so commonplace that they have lost much of their former mystique.

A recent survey conducted in Australia found, for example, that very few people associate cars with status or sex appeal and that most are concerned with reliability and other more "mundane" qualities. 


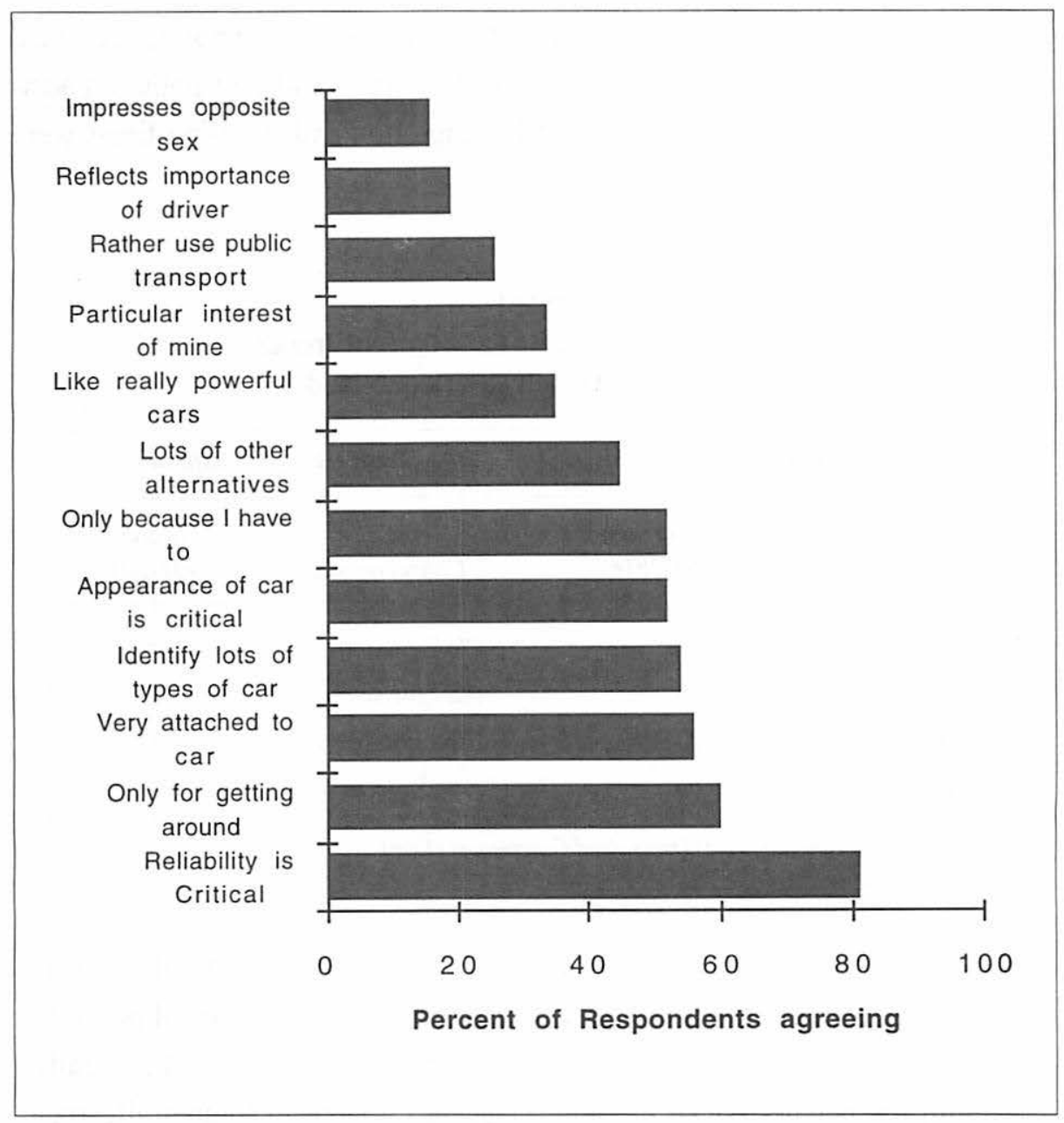

Figure 1. Attitudes to the car: survey of Australian motorists, 1996

For example, only 15 percent thought cars impressed the opposite sex, while 55 percent used cars only because they had to.

While the extent of the private benefits from cars may be leveling out in western countries, the concern about the public costs of car dependence continues to grow in both developed and developing countries. For example, recent 
Transport studies for Sydney (Australia's largest city) and South East Queensland (the fastest growing region) found that, given current trends, air pollution accidents are likely to increase rapidly, while congestion and traveling times were also likely to increase dramatically.

\begin{tabular}{|llll}
\hline \multicolumn{4}{c}{$\begin{array}{c}\text { Table 1 } \\
\text { Public Costs from Private Cars: Current Trends } \\
\text { in Sydney and South East Queensland }\end{array}$} \\
\hline \multicolumn{3}{c}{ Sydney } & \multicolumn{2}{c}{ South East Queensland } \\
\hline Characteristic & \% Increase & Characteristic & 1991-2011 \\
\hline CO Emissions & $1991-2016$ & CO Emissions & 51 \\
Air Quality Decline & 22 & HC Emissions & 27 \\
Fuel Consumption & 23 & NO Emissions & 99 \\
Accident Costs & 66 & Accident Costs & 82 \\
\hline
\end{tabular}

Source: NSW Government (1992); Queensland Government (1996).

Public transport, on the other hand, can be characterized as offering low private mobility benefits but at a lower overall social cost in terms of pollution, congestion, accidents, land requirements, and environmental impact generally.

From the perspective of the public, recent research in Sydney illustrates some of the features desired in a public transport system and the level of satisfaction with current train, bus and taxi services. Sydney has a population of 3.8 million housed mainly in low density suburbs and has Australia's most extensive and heavily-used public transport system, including:

- a large suburban rail system including 275 stations and 1,500 doubledeck rail cars,

- a large network of bus services provided by both public and private bus operators, incorporating over 3,000 buses, 
- some 4,300 taxis, now mostly computer dispatched, and

- an extensive ferry service on the Harbour and Parramatta River.

The results are based on a sample of 300 residents (Douehi 1996) in a typical inner suburb (Leichhardt) and typical outer suburb (Fairfield) of Sydney. The sample covers a wide range of incomes, household types, and lifestyles, ranging from double-income, professional couples with no children (DINKS) to the typical nuclear family, and can therefore be considered broadly representative of attitudes in the larger Australian cities (see Figures 2 and 3).

Research in Perth (Reark and Associates, 1995) and other cities has revealed similar conclusions that current public transport services in Australia are not fully meeting people's needs. In particular:

- Train services are not considered safe, particularly at night and weekends. This is a particular concern among women.

- Bus services are generally inadequate in terms of frequency and reliability and also do not provide for cross-suburban linkages. People also complain of lack of information about arrival times at stops.

- Taxis, while generally convenient (except at times of peak demand), are too expensive for most people to use on a regular basis.

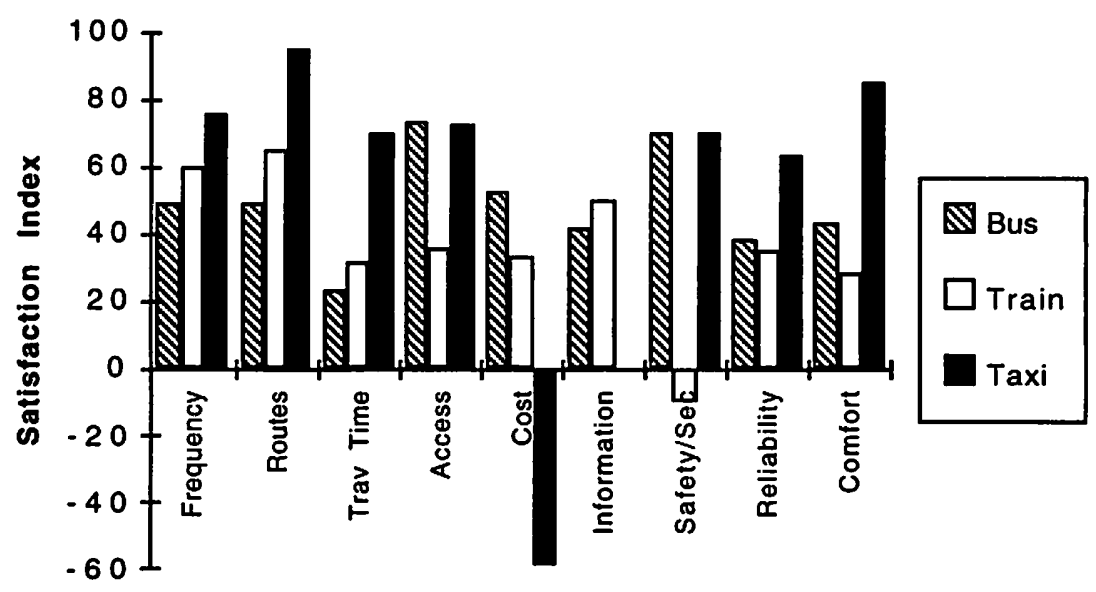

Figure 2. Satisfaction by mode and characteristic (Sydney). 


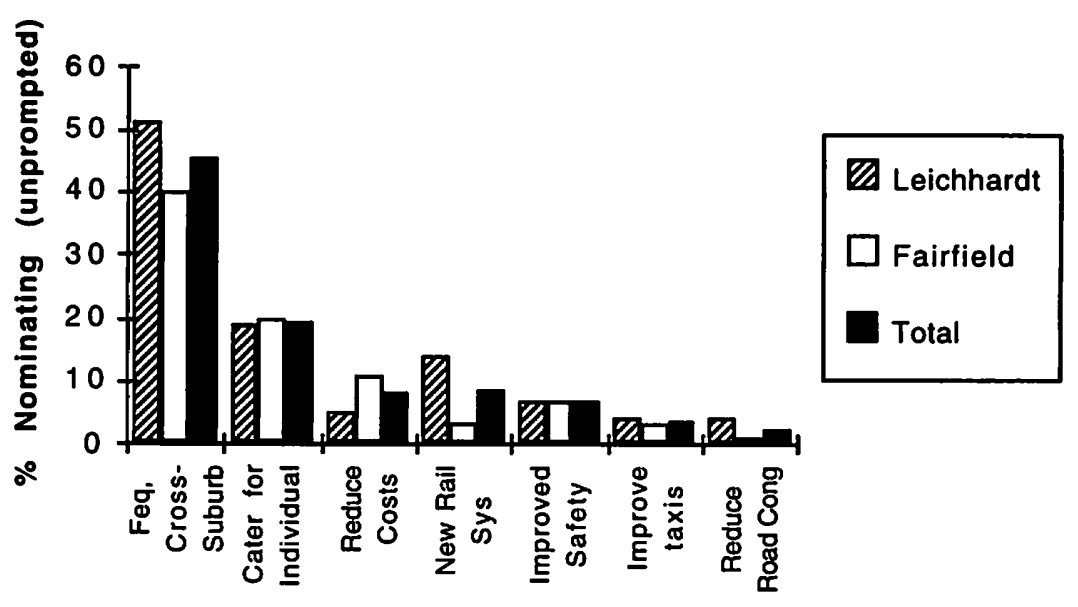

Figure 3. Desired improvements to public transport.

\section{New Solutions to Urban Transport Needs}

Urban transport planners thus face a challenge: how to provide a better overall balance between private benefits and public costs of travel. The ideal transport system would combine low public costs with high private mobility benefits. Unfortunately, we are currently constrained to trading off between public and private modes, both of which have undesirable features. This trade-off fails to move us towards the ideal transport system.

New solutions are needed that can:

- reduce the public costs of private travel, and

- increase the private mobility benefits of public transport.

Such strategies could greatly increase the range of choice available in overall transport terms and move us towards a more ideal system.

\section{Developments in Urban Public Transport}

\section{The Personal Public Transport Concept}

Personal Public Transport (PPT) is a new approach to public transport involving: 
- the introduction of new multi-hire, on-demand services provided by maxitaxis and taxibuses, with a fare structure between that of taxis and scheduled bus services; these new modes would be computer dispatched using the latest multi-hire dispatching software systems;

- the linking of all modes (trains, buses and other scheduled services, and single and multi-hire, on-demand services as well as car and van pooling) into a seamless integrated multimodal system by connecting all vehicle fleets to one or more control centers in real time;

- the provision of real-time information and booking services to individuals by a range of communication channels, including current telephone networks, the internet, and networks of electronic bus stops or kiosks, closely spaced throughout the urban area; and

- the use of contactless smart cards and customer accounts to provide an integrated fare collection and distribution system, which will eventually dispense with the need for cash-based ticketing systems.

The benefits from introduction of a full PPT system include:

- Increased choice and affordability -The need for this is illustrated in Figure 4, which shows the current limited range of choices available (with taxi fares typically four or more times more expensive than bus or rail fares for a typical urban trip), together with the new maxitaxi and taxibus fares (expected to be in the order of 70 percent and 55 percent of taxi fares, respectively).

Thus, the new modes will allow customers a meaningful range of traveling options in terms of fares and levels of service. In particular, on-demand, anywhere-to-anywhere services will be available at around half the fare of current taxis.

- Increased convenience -PPT will increase convenience by:

- allowing people to become account customers of the public transport system, paying all fares by smart card or by account and receiving periodic accounts as happens for electricity, gas or telephone customers; 
Fare

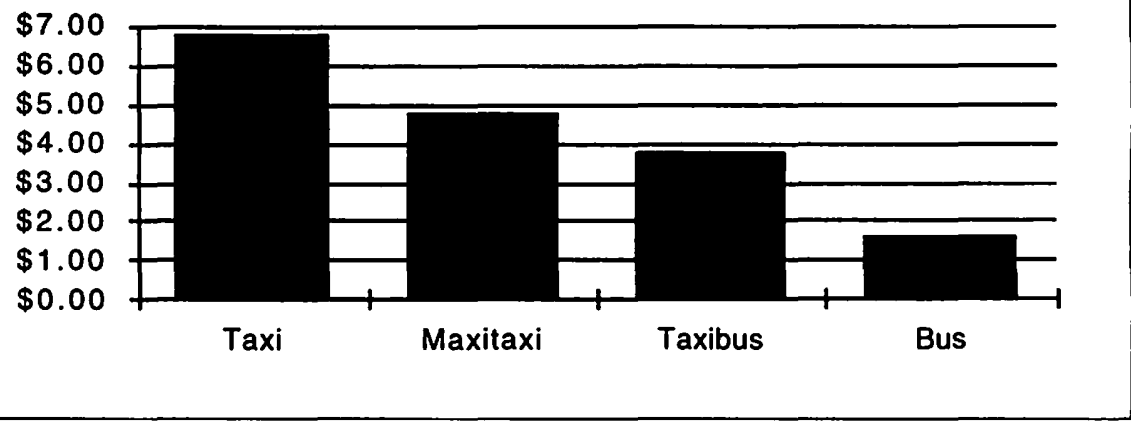

Figure 4. Increasing the range of choice in fare structures.

- providing real-time arrival information of buses at all bus stops-this will overcome one of the key disadvantages of the bus systems in the eyes of the public; and

- making information on all modes available through the one system so that people can make an effective choice between modes or make a journey involving more than one mode. In particular, the network of electronic bus stops will effectively integrate scheduled and on-demand services in space and time. Research in Perth and Sydney, for example, showed that less than 5 percent of bus stops were located close to public telephones and vice versa; this means that a person currently has to choose whether to wait at a bus stop (with no reliable information as to whether they've just missed the bus or if another one is coming), or walk down the street (and risk missing the bus) to find a pay phone to call a taxi.

- Increased safety and security-The use of computer dispatching, booking systems, and AVI systems means that people will be able to book connecting maxitaxi or taxibus services while on a train or express bus, to take them the last few kilometers home or from home to the station or bus. This will reduce the need to wait for an uncertain bus connection and increase the feeling of security 
in traveling by train in particular. Trips booked on the system will also be logged on computer, providing increased security for both passenger and driver.

- Increased efficiency-PPT will improve the efficiency of existing public transport services:

- Rail and express bus systems will be able to utilize PPT to widen the catchment areas of their stations, improving overall patronage.

- Bus operators will benefit from the provision of real-time arrival data at all bus stops and will be able to rationalize their operations by using taxibuses for the lower density traffic and focusing scheduled services on routes with sufficient patronage.

- Taxi operators will be able to provide maxitaxi services using 6-12 seat vehicles and their current booking systems, thus extending their market and better matching surges in demand (e.g., on Friday nights or after rain) through shifting some of the 4-6 seat vehicles between single and multiple hire modes.

In addition, a proportion of vehicles and drivers will be able to switch between courier (parcel express) services and multi-hire passenger services depending on the time of day and business, thus making more efficient use of vehicles, drivers and control systems.

\section{Feasibility Studies}

A number of pre-feasibility and feasibility studies into PPT have now been carried out in Australia, in Perth, Canberra, and Sydney (see, for example, Glazebrook 1995; Glazebrook, Middleton, and Ratcliffe 1994). Key conclusions of these studies include the following.

\section{Technology}

The technology needed for establishing a PPT system includes:

- AVI systems (e.g., GPS-based systems)

- multi-hire dispatch software systems

- automatic booking and inquiry systems

- inexpensive PPT stop facilities or kiosks

- mobile data terminals and radio equipment on vehicles 
All of these systems are now in use in Australia and in many other countries. The remaining requirement is to complete a fully-integrated system, including the integration of existing modes and operators and the provision of new modes, together with an extensive system of PPT stops to make automatic bookings simple and convenient.

\section{Market Demand}

There is likely to be a significant new demand for public transport if a PPT system were introduced, even in areas with high current car ownership (see below).

\section{Performance of the Vehicle Fleets}

Simulation studies undertaken by CSIRO using the Litres Model (Rawling, Smith and Davidson, 1995) indicates that multi-hiring can produce efficiency gains (measured by effective passenger-km per driver/vehicle hour) of 60-100 percent, compared with single-hire taxis. This should enable realistic unsubsidized fares of 65-75 percent of taxi fares for maxitaxi services and 50-60 percent for taxibus services. However, multi-hire, on-demand services on an anywhere-anywhere basis cannot be provided at current bus fares (which are typically 20-30 percent of taxi fares in Australia).

The simulations also showed that with realistic vehicle numbers (matching the anticipated demand), average wait times would be:

- approximately 5.5 minutes for taxis

- approximately 7 minutes for maxitaxis

- approximately 10 minutes for taxibuses

These were considered acceptable by the public, as were the average speeds and deviations for multi-hire services (deviations averaged 20-25 percent from shortest route and were controlled below 30 percent for maxitaxis, and 60 percent for taxibuses by the computer dispatching system).

\section{Financial Feasibility}

Overall, the cost of establishing a suitable pilot in Australian conditions should be approximately $\$ 8-10 \mathrm{~m}$ (US $\$ 6.2-\$ 8 \mathrm{~m}$ ) for the electronic bus stop net- 
work (300-500 stops), together with on-vehicle equipment and control center. Additional costs would be required for covering possible demand shortfalls during the start-up phase. It is assumed that the operators would provide their own vehicle fleets. The financial feasibility suggested that a PPT system could be established to run with no ongoing subsidies other than any specific user-side subsidies (e.g., for pensioners or school children), although it would be preferable to launch a pilot project in an area with sufficient trip density and expand from there.

\section{Institutional Issues}

There are a number of ways in which PPT could be introduced, ranging from a fully publicly-owned-and-run system to a fully privately-owned system. One option would be for the establishment of a joint venture company to own and operate the control center and network of communication systems (e.g., PPT stops), with that company contracting with bus and taxi operators to provide certain numbers of vehicles and drivers for multi-hire operations as well as realtime data on all their operations. Local government could play a key role in brokering a deal between the various parties and, indeed, in helping to cover the cost of some of the in-ground facilities (in much the same way it funds traffic management and local road infrastructure).

\section{Market Research}

A number of market research studies have also been undertaken into the public reaction to the PPT concept in Australia (Douehi 1997; Reark and Associates 1995). These indicate that:

- The public react favorably to the PPT concept, in particular to:

- its flexibility and ability to match their individual travel needs,

- the proposed payment systems (accounts and smart cards),

- the provision of real-time travel information at bus stops,

- the ability to link on-demand and rail services, and

- the ability to provide for cross-suburban, shopping, recreational and other trips for which conventional public transport (trains and buses) are not always suitable. 
- PPT on-demand modes are likely to be used more for non-work trips (where they could capture a mode share of around 8-12 percent) than for work trips (where they might only account for 2-3 percent).

- On the fare structures likely to prove realistic (see above), the share of total on-demand travel is likely to be approximately 20 percent taxi, 40 percent maxitaxi, and 40 percent taxibus.

- PPT could reduce the need for a second car (and, in some cases, for a first car).

- PPT was particularly well-received by older people, women, and teenagers (whose travel needs are not always well catered for at present) and was more likely to be used by white collar than blue collar workers.

\section{Implications of Introducing PPT}

The introduction of new, continuous, multi-hire systems (maxitaxis and taxibuses) would have substantial benefits to the public, particularly for cross suburban trips for which current public transport alternatives are not always convenient.

For example, research into travel patterns in South East Queensland (SEQ, Australia's fastest-growing urban area) reveals that:

- Only 10 percent of motorized trips in SEQ are to or from the Central Business District (CBD); 10 percent are to or from other centers; and 80 percent of trips are "anywhere-anywhere."

- Public transport has a current market share of 22 percent for CBD-oriented trips, but only 4 percent of trips to other centers or anywhereanywhere trips.

- The average car-based trip is around $5 \mathrm{~km}$.

- A typical $5 \mathrm{~km}$ non-CBD-bound trip in the inner suburbs of Brisbane (the capital of Queensland and largest city in South-East Queensland) takes 50 minutes by public transport (including walking, waiting, transfer and in-vehicle time) and costs $\$ 2.25$, while the taxi alternative takes 16 minutes (including waiting) but costs $\$ 8.50$. These are currently the only non-car alternatives (see Table 2). 


\section{Table 2}

Analysis of Typical Inner-Suburb Cross-Suburban Trips in Brisbane

\begin{tabular}{lccccccc}
\hline Typical Trip & Case 1 & Case 2 & Case 3 & Case 4 & Case 5 & Case 6 & Avg \\
\hline $\begin{array}{l}\text { Crow-Flies } \\
\text { Distance (km) }\end{array}$ & 3.63 & 2.75 & 5.75 & 3.75 & 5.75 & 5.50 & 4.52 \\
Total Times: & & & & & & & \\
Public Transport & 55.2 & 55.0 & 49.0 & 48.2 & 50.5 & 43.5 & 50.2 \\
Taxi & 12.0 & 21.0 & 15.0 & 12.0 & 16.0 & 18.0 & 15.7
\end{tabular}

Fares:

$\begin{array}{lrrrrrrr}\text { Public Transport } & \$ 1.40 & \$ 3.00 & \$ 2.80 & \$ 2.00 & \$ 1.70 & \$ 2.60 & \$ 2.25 \\ \text { Taxi } & \$ 6.50 & \$ 12.10 & \$ 8.00 & \$ 6.40 & \$ 8.10 & \$ 9.75 & \$ 8.48\end{array}$

By using a mixture of taxis and regular public transport, passengers could, in effect, have other alternatives (e.g., a mode half way between taxi and public transport).

However, maxitaxis and taxibuses could significantly improve the range and cost-effectiveness of the current options. For example, on an average basis, they could reduce the cost of a typical cross-suburban trip (for a given time budget) by 17-27 percent, or the time required for a given cost by 20-25 percent (see Table 3 and Figure 5).

\section{Prospects}

\section{Implementing PPT}

The biggest difficulty in introducing a full PPT system is the need to integrate all operators in real time and to get cooperation of both bus and taxi industries, which are traditional rivals. The situation is further complicated in Australia by the current franchising-out process involving the breakup of previous government-run monopoly bus services, a process which is occurring in Melbourne, Adelaide, and Perth at present. 


\section{Table 3}

Estimated Travel Times and Fares for New On-Demand Modes

Typical Trip Case 1 Case 2 Case 3 Case 4 Case 5 Case 6 Avg

Total Times:

Maxitaxi

$\begin{array}{lllllll}21.0 & 32.3 & 24.8 & 21.0 & 26.0 & 28.5 & 25.6 \\ 24.9 & 37.5 & 29.1 & 24.9 & 30.5 & 33.3 & 30.0\end{array}$

Taxi Bus

Fares:

Maxitaxi

$\$ 4.23 \quad \$ 7.87 \quad \$ 5.20$

$\$ 4.16$

$\$ 5.27 \$ 6.34$

$\$ 5.51$

Taxi Bus

$\$ 3.25 \$ 6.05 \quad \$ 4.00$

$\$ 3.20 \quad \$ 4.05 \quad \$ 4.88$

$\$ 4.24$

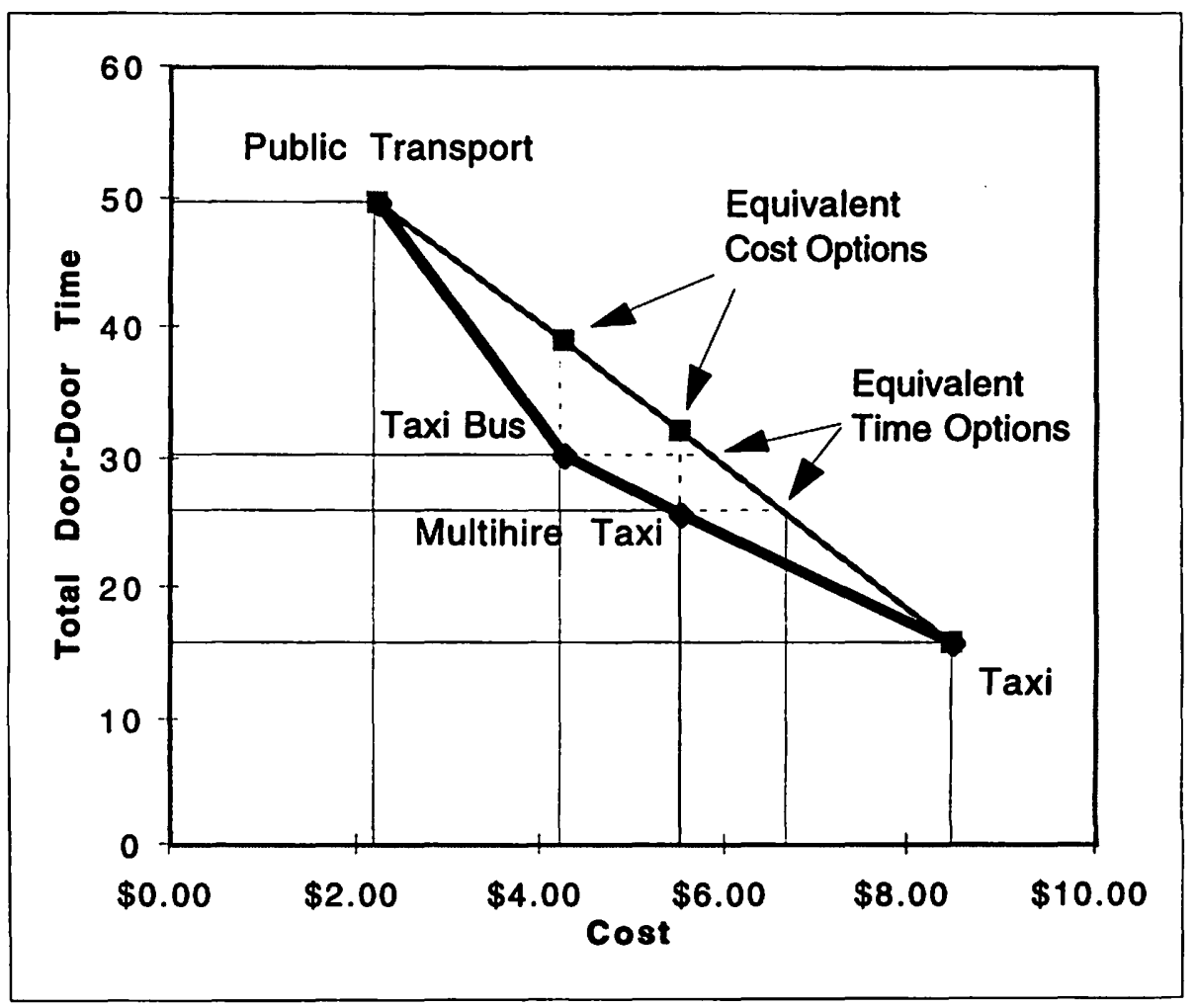

Figure 5. Time-cost tradeoffs-current and future.

Typical $5 \mathrm{~km}$ cross-suburb trip in Brisbane. 
Accordingly, in 1995 the Federal Government, under its Greenhouse 21C program, established an Innovative Urban Public Transport Program to help encourage the establishment of projects such as PPT. Calls for expressions of interest in a national PPT project were made in December 1995, and positive responses were put forward in January by:

- Western Australia (2 submissions),

- the Australian Capital Territory,

- the South Australian Government, in conjunction with Local Government and others, and

- six Local Government Authorities in NSW.

Unfortunately, following a change of National Government in the March 1996 election, the program was discontinued before any funds were allocated.

\section{Prospects in Australia}

Accordingly, no complete PPT system has yet been developed or installed in Australia. However, various projects or initiatives are under way that include particular components of an ultimate PPT system. For example:

- In Perth, a Central Area Transit System (CATS) has commenced, featuring new low-floor midi-buses and the use of real-time arrival time information at specially-equipped bus stops in the CBD. This system uses GPS satellite technology to track the vehicles and a computer system to estimate the arrival of the buses at the next stop.

- In Brisbane, the Brisbane City Council is installing transponders on more than 180 buses to enable them to trigger bus priority at traffic lights on Waterworks Road and to provide location information for real-time arrival time data at selected bus stops.

- Also in Brisbane, the State Department of Transport launched its Integrated Regional Transport Plan for South East Queensland a few months ago. Among other initiatives, this includes major plans for a busway network and plans for developing an integrated multimodal approach to public transport incorporating Personal Public Transport. 
- In Canberra, Action Buses is to sell its existing fleet and lease them back. This will allow them to introduce minibuses into the fleet. There are also plans for running on-demand services.

- Many Local Councils in the Sydney area are taking steps to encourage improved or innovative public transport; for example:

- Leichhardt Council has included contributions for public transport in its latest draft Section 94 plan, while Leichhardt and Fairfield Councils have funded market research into the adequacy of current services and the ways in which this could be improved.

- Willoughby and other councils are installing parking meters and plan to use some of the revenue for improving public transport.

- Councils such as Manly and Sutherland have been arguing for improved services in their areas.

- The taxi industry is continuing to install GPS satellite receivers in its fleets - many fleets are now fitted. To date, this has been used mainly to provide an emergency location system to improve driver safety, but some companies are experimenting with using the location information to track vehicles on a regular basis to aid in dispatching the nearest available taxi, thus improving customer service and fleet utilization. Many taxi operators are also diversifying their fleets; in Queensland, already 10 percent of the vehicles are multi-purpose (5-12 seaters), providing a basis for introducing multi-hire services in the future.

- Adelaide has recently decided to proceed with the MultifunctionPolis project in the northern suburbs. Provision of innovative public transport is likely to be part of this project.

- There are currently several smart card trials under way in Australia, including contactless smart card trials in Western Sydney involving local taxi, bus, and rail operators as well as banks and retail outlets.

- An Australian company, Dynamic Transport Management, has developed one of the world's most advanced dispatching systems for the courier industry capable of handling multi-hire dispatching applications for 
passengers. Virtually all of Australia's taxi industry is now computer dispatched using advanced single-hire dispatching systems, mostly using Raywood equipment. This expertise has already led to export opportunities for both of these companies in the Asia-Pacific region, the United States, Europe, and the Middle East.

Table 4 summarizes some of these developments.

Hence, it is hoped that further developments will enable an integrated approach to be developed that incorporates the full PPT concept with new multihire modes, extensive network of PPT stops, and integration of scheduled and on-demand services in real time.

\section{PPT and PRT-A Comparison}

\section{Capital and Operating Costs of Personal Public Transport}

PPT is essentially an approach based on utilizing current public transport vehicles and adding Intelligent Transport Systems to provide new types of services and to integrate all services in real time into a seamless system from the perspective of the customer.

As such, it is a relatively low capital cost system, with the main expenditure being on communications systems. The on-demand vehicle fleets would be expanded considerably, but these are relatively cheap. No new roads would be required. The total capital cost for a PPT system for a city the size of Sydney (population 3.8 million) and capable of handling at least 5 percent of total motorized trips in the metropolitan area, is estimated in Table 5.

Thus, total capital expenditure for Sydney would be expected to be of the order of A $\$ 1$ billion (US $\$ 800$ million), which would probably be spread over a decade or so. This compares with annual capital expenditure of A\$600 million on the CityRail network, and more than that on major roadworks in Sydney. For example, the following are some of the major projects recently completed or under way at present in Sydney:

- the New Southern Railway (A\$670 million) (under construction)

- the Homebush Bay Rail Line (A\$70 million) (under construction) 
Table 4

Current Trials and Initiatives in Australia

Location

Initiative

Sydney Melbourne Brisbane Perth Adelaide Canberra

Integrated

(non-real time)

Yes

Yes

pass Info System

\section{Computer}

dispatching of

Yes

Yes

Yes

Yes

Yes

Yes

taxis

\begin{tabular}{|c|c|c|c|}
\hline GPS on taxis & Yes & Yes & Yes \\
\hline $\begin{array}{l}\text { GPS/AVI } \\
\text { on buses }\end{array}$ & $\begin{array}{l}\text { Small } \\
\text { trial }\end{array}$ & & $\begin{array}{l}180 \\
\text { buses }\end{array}$ \\
\hline
\end{tabular}

$\begin{array}{lllll}\text { Real-time } & \text { Some } & \text { Some } & \text { Select } & \text { Spec. } \\ \text { arrival } & \text { stations } & \text { stations } & \text { bus stops } & \text { stops } \\ \text { information } & \text { and sev. } & \begin{array}{l}\text { and on } \\ \text { bus stops } \\ \text { trial for }\end{array} & \text { on trial } & \text { in CBD } \\ & & & \\ & & & & \end{array}$

Use of "maxi- Limited Extensive

taxis" by taxi

industry

Use of mini and Extensive Extensive Limited

Com-

midi buses

Franchising of Yes

bus services

Extensive

Under Under

way

way

Smart card trial Yes

Information

kiosk trial

Yes

Yes

- the Ultimo Pyrmont Light Rail Line (\$A60 million) (almost completed)

- the Eastern Distributor (A\$600 million) (about to commence)

- the M5 Motorway (A\$650 million) (just completed)

- the Harbour Tunnel (A $\$ 700$ million) (completed) 


\section{Table 5}

Estimated Capital Cost for a PPT System for Metropolitan Sydney

\begin{tabular}{|c|c|c|c|c|}
\hline Item & $\begin{array}{c}\text { No. } \\
\text { Required }\end{array}$ & $\begin{array}{c}\text { Cost per } \\
\text { Item } \\
A S\end{array}$ & $\begin{array}{l}\text { Total } \\
\text { Cost } \\
A S m\end{array}$ & $\begin{array}{c}\text { Cost per } \\
\text { Capita } \\
A \$\end{array}$ \\
\hline \multicolumn{5}{|l|}{ Control Centers } \\
\hline Regional & 10 & $6 \mathrm{~m}$ & 60 & 16 \\
\hline Main Center & 1 & $20 \mathrm{~m}$ & 20 & 5 \\
\hline Subtotal & 11 & & 80 & 21 \\
\hline \multicolumn{5}{|l|}{ Additional Vehicles } \\
\hline Maxitaxis & 6,000 & 50,000 & 300 & 80 \\
\hline Taxi buses & 4,000 & 100,000 & 400 & 105 \\
\hline Subtotal & 10,000 & & 700 & 185 \\
\hline \multicolumn{5}{|l|}{ Mobile Equipment } \\
\hline Taxis & 4,300 & 2,000 & 9 & 2 \\
\hline Maxitaxis & 6,000 & 3,500 & 21 & 6 \\
\hline Taxi buses & 4,000 & 3,500 & 14 & 4 \\
\hline Subtotal & 14,300 & & 44 & 12 \\
\hline Electronic Bus Stops & 21,000 & 12,000 & 250 & 66 \\
\hline Total & & & 1,074 & 282 \\
\hline
\end{tabular}

While the capital costs for a PPT system would be low, the operating costs for the on-demand components would be relatively high due to the need for drivers and the use of small vehicles. This is reflected in the anticipated fare structures, which are expected to average around $\$ 1.00$ per kilometer for a $4 \mathrm{~km}$ trip for the multi-hire on-demand modes (compared to an average of 50-80 cents per kilometer for the full cost of driving, excluding parking and externality costscongestion, pollution, etc.).

The figure expected in other cities would depend on factors such as population density, wage structures, ownership models assumed for the on-demand fleets, road congestion levels, etc. 
In higher-density cities, such as are typical in Europe or Asia, average seat occupancies will be higher, although this will be counterbalanced by lower average travel speeds. Low-density cities such as those found in the U.S. will generally have longer trips, higher speeds and somewhat lower occupancy factors.

\section{Capital and Operating Costs of Personal Rapid Transport}

Personal Rapid Transport is a generic name for systems combining the use of small vehicles (to provide flexible and personalized transport) with guideway and control systems to allow those vehicles to move without drivers.

Generally, such systems can be expected to exhibit (relatively) high capital costs, particularly if grade separation from existing streets and pedestrians is required, but low operating costs (due to the automatic control systems). For example, Table 6 compares capital costs for PPT and some PRT systems examined in relation to the Gold Coast in Queensland.

The particular cost structures will depend on the particular city or application concerned, and the details of the particular system adopted.

Table 7 summarizes some of the main features of PRT vs. PPT.

\begin{tabular}{|c|c|c|c|}
\hline \multicolumn{4}{|c|}{$\begin{array}{c}\text { Table } 6 \\
\text { Comparison of Capital Costs: PPT vs. PRT }\end{array}$} \\
\hline & PPT (a) & PRT (b) & $P R T$ (c) \\
\hline Total Capital Cost & A $\$ 90 \mathrm{~m}$ & A $\$ 140 \mathrm{~m}$ & A $\$ 240 \mathrm{~m}$ \\
\hline Estimated Ridership & 16 million & 16 million & 20 million \\
\hline Capital Cost/Rider & A $\$ 6$ & A $\$ 9$ & A $\$ 12$ \\
\hline \multicolumn{4}{|c|}{$\begin{array}{l}\text { Sources: } \\
\text { (a) Author's stimate; assumes full PPT multihire system capturing 4-5\% of motorized trips } \\
\text { in Gold Coast area. Includes cost of vehicle fleets required. } \\
\text { (b) Austrans System (based on estimates provided by Austrans); captures high percentage of } \\
\text { line-haull trips in densely used coastal strip. } \\
\text { (c) Overhead Suspended PRT System evaluated for Gold Coast; captures high percentage of } \\
\text { line-haul trips in densely used coastal strip. }\end{array}$} \\
\hline
\end{tabular}




\section{Table 7}

Comparison between Key Characteristics of PRT and PPT

\begin{tabular}{lcc}
\hline \multicolumn{1}{c}{ Characteristic } & PRT & $P P T$ \\
\hline Capital Cost & High & Low \\
Operating Cost & Low-Medium & High \\
& & (On-demand modes) \\
\hline
\end{tabular}

Potential Suitability for:

- Specialist applications (e.g., airports)

High

Med

- Downtown distributors

High

Med

- High volume links

Med

Med-Low

(on-demand modes)

- Purpose-built new town developments

Med

Med

- General suburban areas

Low

High

Ease of retrofitting into

Low

High

existing urban environments

This suggests that PRT systems are likely to first be established in specialized areas (such as links between airport terminals and surrounding car park areas, new town developments, or resort areas), while PPT could be installed virtually anywhere. In both cases, however, initial resistance is likely from current transport operators unless they can be incorporated into the solution (this is much more likely with PPT than automated systems such as PRT).

PRT systems are also likely to be more suitable in high income communities where wage rates are high and, hence, competing transport systems are expensive, or where congestion is so bad that politicians are forced to undertake major investments to solve the problems. 


\section{Evolution of our Cities-A Simplified Paradigm}

Where do PPT and PRT fit into the bigger picture?

In very simplified terms, our society can be seen as evolving through various stages over the last few centuries, from the pre-industrial through the industrial and post-industrial ages to the future "communitarian" age.

As discussed by Lepani et al. (1995), this process of evolution has economic, social/psychological, and physical (including urban structure and transport systems) dimensions; it also reflects a general principle of nature for increasing overall structural complexity, as illustrated below.

Our urban structures have been transformed from villages and small towns, to the high-density but structured cities of the industrial age, then to the sprawling suburban regions of today. This process is still continuing in countries such as China, India, and Indonesia, where rural-urban migration continues at a high rate.

In urban transport terms, we have seen first the rise of mass public transport systems (predominantly heavy rail and electric tram) in the industrial age, followed by the rise of mass private transport in the form of the car in the postindustrial age.

The social parallel was the demise of the local community and the rise of mass movements, class structures, and nationalism in the industrial age, followed by the rise of the cult of the individual. In psychological terms, the industrial age was characterized by conformity; the post-industrial age was characterized by freedom and its resultant chaos.

The costs of the current post-industrial age in social, environmental, and psychological terms are beginning to be understood more widely. As this happens, future societies will begin to emerge. These are likely to be based on new value systems in which environmental and social awareness is more apparent than it is today, with correspondingly less emphasis on individual consumption. There is likely to be both increasing global connectivity at one level, and increasing local connectivity at another, with a renewed focus on belonging. However, unlike previous village societies, people will have greater flexibility to choose 
Table 8

Economic, Social/Psychological, and Physical Evolution:

A Simplified Model

\begin{tabular}{|c|c|c|c|c|}
\hline $\begin{array}{l}\text { Stage of } \\
\text { Evolution } \\
\text { Dimension }\end{array}$ & $\begin{array}{c}\text { Pre- } \\
\text { Industrial }\end{array}$ & Industrial & $\begin{array}{c}\text { Post- } \\
\text { Industrial }\end{array}$ & $\begin{array}{c}\text { Future } \\
\text { Communitarian }\end{array}$ \\
\hline Economic & $\begin{array}{l}\text { Feudal; } \\
\text { limited trade; } \\
\text { small-scale } \\
\text { production; }\end{array}$ & $\begin{array}{l}\text { Nation states; } \\
\text { global trade; } \\
\text { economies of } \\
\text { scale; } \\
\text { producer } \\
\text { economics }\end{array}$ & $\begin{array}{l}\text { Borderless } \\
\text { world; } \\
\text { economies of } \\
\text { scope; } \\
\text { consumer } \\
\text { economics }\end{array}$ & $\begin{array}{l}\text { Integrated } \\
\text { world; } \\
\text { economics } \\
\text { and ecology; } \\
\text { quality of life } \\
\text { economics }\end{array}$ \\
\hline $\begin{array}{l}\text { Social/ } \\
\text { Psychological }\end{array}$ & $\begin{array}{l}\text { Highly-structured } \\
\text { but inward } \\
\text { looking; } \\
\text { religious view }\end{array}$ & $\begin{array}{l}\text { Class-structured; } \\
\text { but increasingly } \\
\text { open }\end{array}$ & $\begin{array}{l}\text { Individualistic; } \\
\text { high levels of } \\
\text { mobility and } \\
\text { stress }\end{array}$ & $\begin{array}{l}\text { Reconnected } \\
\text { societies with } \\
\text { greater } \\
\text { emphasis on } \\
\text { localism and } \\
\text { belonging }\end{array}$ \\
\hline $\begin{array}{l}\text { Urban } \\
\text { Structure }\end{array}$ & $\begin{array}{l}\text { Villages and } \\
\text { small towns }\end{array}$ & $\begin{array}{l}\text { Major } \\
\text { industrial cities }\end{array}$ & $\begin{array}{l}\text { Metropolitan } \\
\text { regions }\end{array}$ & $\begin{array}{l}\text { Urban village } \\
\text { networks }\end{array}$ \\
\hline $\begin{array}{l}\text { Urban } \\
\text { Transport }\end{array}$ & $\begin{array}{l}\text { Walk, horse- } \\
\text { drawn vehicles }\end{array}$ & Mass transit & Automobile & PPT, PRT \\
\hline $\begin{array}{l}\text { Physical } \\
\text { Analogy }\end{array}$ & Solid & Liquid & Gas & $\begin{array}{l}\text { Organic } \\
\text { molecure }\end{array}$ \\
\hline Energy Use & Low & Medium & High & Medium \\
\hline $\begin{array}{l}\text { Entropy } \\
\text { (Disorder) }\end{array}$ & Low & Medium & High & Medium \\
\hline $\begin{array}{l}\text { Intercon- } \\
\text { nectedness }\end{array}$ & Low & Medium & Medium & High \\
\hline $\begin{array}{l}\text { Overall } \\
\text { Structural } \\
\text { Complexity }\end{array}$ & Low & Medium & Medium & High \\
\hline
\end{tabular}


among a range of communities, with distinct but more sustainable lifestyles, technologies and value systems.

If this broad thesis is accepted, then it is likely that new urban transport systems that provide a better overall balance between individual mobility and environmental and community welfare will emerge. PPT and PRT are likely to be strong contenders for such systems.

\section{References}

Douehi. 1997. An Analysis of Public Transport Utility and Feasibility of Personal Public Transport in Leichhardt and Fairfield. Reports produced for Leichhardt and Fairfield Councils.

Glazebrook and Associates. 1995. Personal Public Transport for Canberra. Pre-Feasibility Report. Report prepared for the ACT Department of Urban Services, March. Glazebrook, G., A. Middleton, and M. Ratcliffe. 1994. Personal Public Transport for

Perth. Proceedings of the First World Congress on Intelligent Transport Systems.

Paris, December: 3032-3039.

Glazebrook, G. 1996. Oz public transport goes personal. ITS International. Issue No 4, London, March: 94-95.

Lepani, B., et al. 1995. The Ryde Urban Villages Study. Report prepared for Ryde City Council (Sydney).

NSW Government. 1992. Future Directions Study for Sydney. Report prepared for NSW Roads and Traffic Authority.

Queensland Government. 1996. Integrated Regional Transport Plan for South East Queensland. Draft Discussion Report.

Rawling, M., J. Smith, and I. Davidson. 1995. Modelling of Personal Public Transport in a Multi-Mode Service Environment. Proceedings from the International Conference on Application of New Technology to Transport Systems. Melbourne, Australia. May: 167-178.

Reark and Associates. 1995. Personal Public Transport for Perth: Market Research. Report prepared for WA Department of Transport, East Perth Redevelopment Authority and Telecom Australia. 


\section{About the Authors}

Garry GlazebrooK is an Associate with Booz-Allen \& Hamilton (Aust) Limited in Sydney, Australia.

Sam Subramaniam is an Associate with Booz-Allen \& Hamilton Limited in McLean, Virginia. 